\author{
María Stella Toro Céspedes \\ Universidad de Chile, Chile
}

\title{
Las mujeres de derecha y las movilizaciones contra los gobiernos de Brasil y Chile (1960 y 1970)
}

Resumen: A 40 años del golpe de Estado ocurrido en Chile y a 50 años del golpe ocurrido en Brasil (1964,) resulta interesante analizar y comparar las movilizaciones y acciones de protesta y desestabilización que encabezaron las mujeres de derecha contra los gobiernos de Goulart y Allende. En ambos países desarrollaron campañas en contra de gobiernos constitucionalmente elegidos, para lo cual se agruparon, recibieron apoyo, establecieron alianzas con otros sectores, salieron al espacio público, exigieron la renuncia de los presidentes y llamaron al resto de las mujeres a manifestarse en contra del marxismo y en defensa de la patria, el orden y la familia. Las actuaciones de estas mujeres y su efectividad estuvieron profundamente marcadas por la defensa de los roles tradicionales de género y por concepciones de la participación política femenina que tendían a negar el carácter político de la actuación de las mujeres.

Palabras Clove: Género; dictaduras; participación política.

(c) (C) Esta obra tem licença Creative Commons.

\section{Introducción}

Tanto en Brasil como en Chile, los sucesos que antecedieron a los golpes militares estuvieron marcados por un significativo proceso de polarización política y social, en que se fueron extremando las posturas de los distintos sectores que los protagonizaron. Algunos defendieron los gobiernos que habían sido elegidos y los proyectos que estos sustentaban, otros se opusieron a ellos y demandaron la intervención de las fuerzas armadas. En estas dos experiencias de quiebre institucional, la lucha política se dio entre los partidos políticos; en las organizaciones 
gremiales y ciudadanas; en las calles y en los cuarteles militares; llegando a altos grados de tensión, en medio de una profunda división política que estuvo acompañada por problemas económicos y por presiones internas y externas (en especial del gobierno de Estados Unidos) que facilitaron el quiebre de la democracia en ambos países.

Los sectores que conjuraron en contra de estos gobiernos, comprendieron que necesitaban de una base social que apoyara la oposición y movilización contra ellos, para lo cual impulsaron la movilización de aquellos sectores que se consideraron afectados por las medidas implementadas por los gobiernos de Goulart y Allende. Los sucesos que antecedieron a los golpes militares de 1964 y de 1973 estuvieron marcados por significativos procesos de polarización y violencia política y social, que por lo general tuvieron entre sus expresiones más visibles la puesta en marcha de campañas comunicacionales contra los gobiernos elegidos democráticamente; y la realización de manifestaciones públicas que muchas veces desembocaron en enfrentamientos callejeros, además del llamado directo a la renuncia de los presidentes elegidos y a la intervención de las fuerzas armadas.

Uno de los sectores que se mantuvieron movilizados de manera masiva y constante antes de los golpes de estado en Brasil y Chile fueron las mujeres de derecha, quienes desarrollaron sendas campañas en contra de los gobiernos de Joao Goulart y Salvador Allende, para lo cual se agruparon entre si, establecieron alianzas con otros sectores sociales y políticos, salieron al espacio público y llamaron al resto de las mujeres a manifestarse en defensa de los valores y principios que consideraron transgredidos. En los dos casos, a partir de un discurso público que buscaba resaltar que sus organizaciones y sus acciones, no estaban inspiradas por afanes políticos o ideológicos, sino más bien por el llamado, casi 'natural', que sentían de defender a sus familias (y sus patrimonios) ante la amenaza de los gobiernos de izquierda.

El llamado a las mujeres en tanto madres, esposas y dueñas de casa a salir a las calles no se hizo esperar, unas con el rosario en la mano y otras golpeando cacerolas mostraron de manera pública su rechazo a las políticas de Estado y demandaron de manera directa la intervención de los militares. La masividad de sus convocatorias y la efectividad de las formas de acción que desarrollaron las volvió un ejemplo de las luchas de las mujeres de derecha del continente, sin embargo, las trayectorias y los desenlaces que tuvieron las intervenciones militares, también ayudaron a que su accionar quedara subsumido dentro de un proceso que finalmente fue protagonizado por otros, (las fuerzas 
${ }^{1}$ Margaret POWER, 2008, p.115.

armadas), apareciendo más bien como sectores que fueron manipulados, siendo que tuvieron un rol importante en la desestabilización de ambos gobiernos y en la justificación de los golpes de Estado.

La importancia de la actuación de las mujeres de derecha en la conformación de una oposición activa y pública a regímenes de determinadas características, además de la complejidad de los procesos que motivaron sus acciones, ha sido analizada por la historia de manera reciente, lo que lleva a desafíos importantes en el campo de la investigación histórica. Para efectos de este texto, se optó por tomar parte de las experiencias desarrolladas en Brasil y Chile, pues cuentan con elementos que permiten realizar una comparación que da cuenta de formas de actuar y de pensar similares, pues incluso se estima que hubo algún grado de conexión entre ambas experiencias, como señala Margaret Power.

Las semejanzas entre los movimientos femeninos anti Goulart y anti Allende plantean la posibilidad de un vínculo político entre ellos. Tanto en Chile como en Brasil, la oposición conservadora a los gobiernos elegidos patrocinó la formación de movimientos cívicos anticomunistas que promovieron la participación y el liderazgo de las mujeres. En ambos países, las mujeres conservadoras apoyaron el derrocamiento de gobiernos elegidos democráticamente y aplaudieron la toma del poder por las fuerzas armadas. ${ }^{1}$

La actuación de las mujeres de derecha se devela como un ámbito en que aparecen diversas preguntas, en particular en lo referente a las subjetividades políticas que han construido, qué las motiva, cuáles son sus concepciones políticas, cómo se conciben a si mismas; son sólo algunas de las preguntas que nos pueden ayudar a comprenderlas más allá de los roles tradicionales que se empeñaron en preservar.

\section{Los quiebres democráticos en Brasil (1964) y Chile (1973): Antecedentes generales}

Los procesos de participación y articulación social y política que se propagaban en la región entre las décadas de 1960 y 1970 influyeron en el desarrollo político de los países americanos, los actores sociales se habían diversificado, las demandas de integración se habían extendido y algunos sectores políticos de izquierda apuntaban a la instalación y/o aceleración de procesos revolucionarios. En este contexto, parte importante de los discursos desarrollados por las derechas y por las mujeres 
manifestaron su oposición a la influencia de ideas foráneas, señalando que no querían volverse otra Cuba u otra Unión Soviética, lo que de alguna manera puede expresar cómo las polarizaciones propias de la Guerra Fría atravesaron las cotidianeidades de diversos sectores sociales, expresándose en este caso en el deseo de dar la 'pelea' contra esas ideas, como señala una de las mujeres entrevistadas en Chile por Ivonne Berliner:

... yo comencé desde el comienzo... 1970... Sergio estaba becado en Europa y yo con los dos niños sola (llena de ideas positivas y negativas)... pensaba como defenderme (si sabía de qué), solo por lo que he leído del comunismo y la influencia ideológica recibida por el medio ambiente... Mi miedo al comunismo me provocó a pelear y pelear tremendamente y no dejar el país e irme al extranjero, como algunos conocidos hicieron en $1970 .^{2}$

En este contexto fue adquiriendo cada vez más importancia la llamada Doctrina de Seguridad Nacional (desarrollada por Estados Unidos), que postulaba la necesidad de que las Fuerzas Armadas se encargaran de mantener el orden interno, a través del control de los enemigos de cada nación, los que en el marco de la Guerra Fría estaban representados por los partidos, movimientos, organizaciones e ideologías que se denominaban o entendían como cercanas al comunismo. De esta manera, para los sectores que compartían estas ideas, los 'enemigos' pasaron a estar dentro de sus propios países. Situación que se reflejó en los acontecimientos vividos en Brasil y en Chile, pues en ambos casos las Fuerzas Armadas aplicaron la Doctrina de Seguridad Nacional y cada uno de estos golpes militares contó con la aprobación, el apoyo y la intervención de los organismos de seguridad de EEUU.

En materia de política interna, en 1960, se había producido en Brasil la elección de Jânio Quadros, su campaña había estado centrada en el combate de la corrupción, la condena moral y política de la intervención sindical en los aparatos de gobierno y el repudio al intervencionismo económico por parte del Estado, al que

${ }^{3}$ Tulio HALPERIN DONGI, 1999, p. $569-70$. responsabilizaba de la alta inflación en el país, ${ }^{3}$ pero a la vez también había tomado algunas ideas inspiradas en la tradición populista, como la independencia en materia de relaciones internacionales, lo que generó sospechas entre algunos sectores (incluso que lo habían apoyado) al igual que su estilo personalista, en especial cuando decidió, en 1961, condecorar a Ernesto Guevara de paso por Brasil.

La intensidad de los conflictos que se desataron entre Quadros y sus opositores pusieron de manifiesto la necesidad de contar con mayores atribuciones, en virtud de lo cual 
${ }^{4}$ Thomas E. SKIDMORE y Pete H. SMITH, 1996, p. 194.

\footnotetext{
5 "Este era el propósito de la propuesta concesión del derecho de sufragio a la tropa y el de organización sindical a los suboficiales del ejército; esta última iniciativa era encontrada particularmente alarmante por los oficiales, y contribuyó decisivamente a debilitar el apego al orden constitucional de sector llamado legalista, que en 1961 había asegurado el acceso de Goulart a la presidencia contra la oposición de buena parte de sus camaradas de armas". HALPERIN DONGI, 1999, p.572.
}

Jânio Quadros presentó su renuncia ante el Congreso en agosto de 1961. Para algunos autores, Quadros esperaba que su renuncia fuera rechazada, lo que en definitiva podía llevar a que se le concedieran mayores atribuciones. ${ }^{4}$ Sin embargo, sucedió lo contrario, su dimisión fue aceptada, quedando vacante el puesto de presidente, el que fue ocupado por el vicepresidente, João Goulart.

La asunción a la presidencia de João Goulart no estuvo exenta de problemas, pues representaba las políticas laboristas de Getulio Vargas, de quien había sido Ministro del Trabajo en la década de 1950. Para facilitar la toma del mando y establecer garantías a los sectores que se le oponían, se estableció un compromiso que apuntaba a la entrega de mayores atribuciones al Congreso, a través de la instauración de un régimen parlamentario. João Goulart ocupó la presidencia de Brasil con poderes limitados, pero una vez asumido el mando se dedicó a preparar un plebiscito que permitiera el reestablecimiento del régimen presidencial, el que se efectuó en 1963. Luego de eso, se aprontó a enfrentar la crítica situación económica en que se encontraba el país, en especial por los altos y prolongados índices inflacionarios y el déficit de la balanza de pagos, para lo cual conformó un equipo encabezado por Celso Furtado. Según el historiador Tulio Halperin Dongi, este programa fue abandonado producto de la resistencia que generó entre los sindicatos y la necesidad de Goulart de ampliar su base de apoyo social entre sectores que tradicionalmente no se habían movilizado, lo que, también, lo impulsó a considerar la demanda de sindicalización que había surgido entre algunos sectores del ejército, decisión que le significó el alejamiento y oposición de sectores de la oficialidad que habían apoyado su asunción a la presidencia. $^{5}$

Estas no fueron las únicas medidas que generaron tensiones, también enfrentaron una fuerte oposición aquellas que apuntaban a la concesión del voto a los analfabetos, la legalización de la sindicalización campesina y la adopción de un programa de reforma agraria. Hacia 1964 las movilizaciones contrarias a las políticas de João Goulart, se habían extendido hacia los sectores medios urbanos, encontrando una de sus mayores expresiones en las Marchas de la Familia, con Dios por la Libertad. Durante ese mismo año la oposición intentó inhabilitar al presidente en el Congreso, pero no contó con los votos suficientes. Sin embargo, la conspiración militar ya era inminente y era apoyada por el embajador de EEUU en Brasil (Lincoln Gordon) y por su agregado militar (Vernon Walters). El 31 de marzo estalló una revuelta militar en Minas Gerais que se extendió rápidamente por el resto del país, y João Goulart huyó al 
${ }^{6}$ Entre las razones que se han entregado para comprender el quiebre institucional en Brasil se encuentra el recelo de las elites a la ampliación del espectro político a que estaban dirigidas algunas de las medidas del gobierno de Goulart. Sobre este punto Skidmore y Smith, señalan: "... en 1964 Goulart presentó o pareció presentar una amenaza más fundamental. Al movilizar a los campesinos y a los obreros, y utilizar una retórica radical, parecía estar creando las condiciones para una amplia alianza de clase entre éstos contra el orden socio-económico establecido. El carácter repentino y la simultaneidad de estos movimientos asombraron y alarmaron a las elites y los observadores, que rechazaron las perspectivas de unas alteraciones de carácter comunista de tan largo alcance en la estructura política del país. No resultaba aceptable una coalición de clase amplía". SKIDMORE y SMITH, 1996, p. 196.

${ }^{7}$ POWER, 2008, p. 23-5.

${ }^{8}$ Jorge Alessandri obtuvo un $34,9 \%$ y Radomiro Tomic un $27,8 \%$. exilio en Uruguay. El 1 de abril se declaró vacante la presidencia y accedieron a ella los militares conspirados y sus aliados civiles, siendo designado como presidente el general que encabezó el levantamiento militar, Humberto Castello Branco. ${ }^{6}$

Por su parte, en Chile, se vivía un proceso progresivo de ampliación de la participación ciudadana, que a lo largo del tiempo posibilitaría el ascenso de las fuerzas de izquierda al poder por la vía electoral, situación que ya se vislumbraba desde las elecciones de 1958, donde, a pesar de que los sufragios favorecieron al candidato conservador, Jorge Alessandri, su triunfo se produjo a partir de una escasa diferencia de votos con Salvador Allende. A lo que se sumaba la instauración de una tercera fuerza política de centro representada por la Democracia Cristiana (DC), que en las elecciones siguientes, en 1964, llegó a la presidencia bajo la promesa de realizar una 'revolución en libertad'. El triunfo electoral de la Democracia Cristiana fue avalado, en principio, por la derecha, ya que en la práctica retiro su adhesión al candidato que buscaba suceder a Alessandri.

Los procesos que se estaban desarrollando en Chile también fueron mirados con atención por el resto del mundo, en especial por EEUU, que luego del golpe militar en Brasil fue dejando de lado las políticas preventivas que se habían desarrollado en el marco de la Alianza para el Progreso. La intervención de Estados Unidos en Chile apuntó en un principio a evitar el establecimiento de un gobierno de izquierda, por lo que se trató de intervenir desde temprano a través del apoyo de aquellos sectores que podían frenar u oponerse al triunfo de estas fuerzas, situación que se expresó en los procesos electorales de 1964 y 1970, a través del apoyo económico a las candidaturas contrarias a Salvador Allende. Sobre la intervención de EEUU en el proceso político chileno, Margaret Power, señala lo siguiente:

El informe del Comité Church, de 1975, relativo a la acción encubierta de Estados Unidos en Chile, que emitió el Senado de Estados Unidos, da pormenores de los intentos que hizo el gobierno de ese país para impedir que Allende ganara las elecciones de 1964 y 1970, y sus iniciativas dirigidas a sabotear al gobierno de la UP, luego del triunfo de Salvador Allende en 1970. El informe establece que Washington había apoyado a las mujeres chilenas y sus iniciativas contra Salvador Allende, desde los primeros años de la década de $1960 .^{7}$

El gobierno de la Democracia Cristiana terminó con importante tensiones sociales, políticas y económicas. En las elecciones siguientes (1970) triunfó Salvador Allende con el $36,3 \%$ de los votos, ${ }^{8}$ quien, pese a no obtener la mayoría absoluta, fue ratificado por el Congreso, bajo el compromiso 
de que se mantendría dentro de los marcos establecidos por la Constitución, y que la realización de reformas estructurales sólo se llevarían a cabo a través de la vía legislativa.

Desde antes de la asunción al mando de Salvador Allende, los sectores que se le oponían comenzaron a tejer distintas tramas para evitar que tomara el poder y luego para desestabilizar al gobierno de la Unidad Popular, un ejemplo extremo de esto fue el secuestro y asesinato, por parte de un grupo de extrema derecha, del Comandante en Jefe del Ejército, el general René Schneider, en octubre de 1970, a pesar de lo cual Allende fue proclamado por el Congreso en noviembre de ese mismo año.

La polarización política se produjo luego del primer año de gobierno, hay consenso en señalar, que el primer año fue más tranquilo de lo que se esperaba, logrando inclusive la aprobación unánime de uno de los proyectos emblemáticos del programa de la UP, como era la nacionalización del cobre. Además de esto, se aumentaron los salarios, lo que generó un alza en la demanda de productos, pero esta no estuvo acompañada por un aumento de la producción, situación que se vinculó a la negativa de los empresarios para responder a la demanda, pues consideraban que sus empresas podían ser expropiadas por el Estado.

Si bien durante el primer año de gobierno se produjo una disminución de la cesantía, un alza en los salarios y un aumento de la capacidad de consumo de la ciudadanía, fuertes problemas económicos afectaron al país en los años posteriores, lo que se vinculó, además, con el bloqueo comercial y financiero que le fue impuesto por EEUU, el que influyó en que la situación de la población se fuera precarizando durante los últimos dos años del gobierno. Todo ello se expresó en un fuerte desabastecimiento, sabotaje económico, acaparamiento de productos, explosión del mercado negro y una alta inflación, que hacia 1973 se estimaba del orden de un 150\%. Estos hechos fueron tensionando el apoyo al gobierno y exacerbando a los opositores, pues el acceso a bienes básicos de consumo se volvió cada vez más difícil, situación que suele ser relevada en los discursos de las mujeres que se movilizaron en contra de la Unidad Popular. De esta manera, una de las imágenes que subsiste en ellas es haber tenido que hacer largas filas para conseguir algún alimento o haber recurrido al mercado negro y al acaparamiento de productos, sin embargo sus primeras movilizaciones se produjeron antes que el desabastecimiento.

Las tensiones sociales también se expresaron en otros ámbitos, en especial en las huelgas que efectuaron algunos sindicatos y gremios de carácter estratégico, como fue el 


\begin{abstract}
${ }^{9}$ Sobre la importancia de las interacciones que establecieron las elites con otros sectores sociales, Skidmore y Smith, manifiestan: "La izquierda obtenía su apoyo principalmente de la clase obrera urbana. Se encontró con la oposición de una clase alta cohesionada, cuyos componentes del sector agrario y de la industria estaban unidos por lazos familiares e intereses comunes, y esta elite unificada fue capaz de obtener el apoyo de los grupos de los sectores medios (y de algunos campesinos tradicionales) y, lo que es más importante de todo, de los activistas militantes de las clases medias y bajas, como tenderos $y$ camioneros en una postura común contra el orden socialista". SKIDMORE Y SMITH, 1996, p.155-6. ${ }^{10}$ Algunas de las razones, que con que se ha buscado explicar el golpe de Estado en Chile se relacionan con las mencionadas para el caso de Brasil, en especial en lo referente a la oposición de las elites a la incorporación de los sectores marginados del sistema político tradicional. Halperín Dongui, señala: "Aunque el conflicto político zanjado por la intervención militar no había desbordado los canales constitucionales, lo que había estado en juego con él, desde la perspectiva de las clases altas y medias, e ra su supervivencia misma: a través de la desbordada insolencia plebeya tanto como de las dificultades para surtir su mesa creían haber conocido el anticipo de una catástrofe irreparable que hubiera significado para ellas un desenlace desfavorable..." HALPERIN DONGI, 1999, p.649. "POWER, 2008, p.33.
\end{abstract}

caso de la movilización protagonizada por mineros y administrativos de la mina de cobre de el Teniente, y de las huelgas realizadas por los transportistas, las que estuvieron encabezadas por los empresarios camioneros que criticaban la falta de combustibles y las dificultades que enfrentaba su sector por los problemas que tenía el país, lo que volvió más crítica la situación de desabastecimiento. Estas movilizaciones fueron apoyadas por las mujeres de derecha, lo que favoreció la generación de alianzas entre los distintos sectores opositores. ${ }^{9}$

A pesar de la situación crítica que se vivía en el país, en las elecciones parlamentarias de marzo de 1973, la Unidad Popular alcanzó un $43 \%$ de los votos, lo que manifestaba una adhesión todavía alta, pero en un contexto marcado por las confrontaciones entre distintos sectores, a lo que se agregó una serie de movilizaciones y de enfrentamientos callejeros y la fuerte crítica al proyecto educativo de la UP, la Escuela Nacional Unificada (ENU). Además de un primer intento de alzamiento militar a fines de junio de 1973, el que fue paralizado por el Comandante en Jefe de Ejército, general Carlos Prats, lo que lo llevó a enfrentar una fuerte oposición por parte de las mujeres de derecha y de las esposas de los oficiales que realizaron movilizaciones para demandar la intervención del ejército y su salida. Prats finalmente renunció.

Las posibles salidas que buscó Salvador Allende a la fuerte oleada de conflictos que sacudían al país estuvieron encaminadas primero por la búsqueda de acuerdos políticos que no prosperaron. También, se ha señalado que en vísperas del golpe de Estado planeaba convocar a la realización de un plebiscito para que fuese la ciudadanía la que se pronunciara en torno a los caminos a seguir, pero la conspiración, al igual que en Brasil, ya era inminente y tuvo su máxima expresión en el golpe militar que efectuaron las Fuerzas Armadas chilenas el 11 de septiembre de 1973.10

\section{Las mujeres de derecha: Motivaciones para organizarse}

Las mujeres han apoyado regímenes fascistas, dictaduras militares brutales y movimientos racistas. Con su apoyo, estos regímenes derechistas han logrado el poder y han puesto en práctica políticas de represión... y las mujeres han brindado ese apoyo en nombre del patriotismo y la maternidad, conceptos que se prestan a una diversidad de interpretaciones y de usos. ${ }^{11}$

Una de las primeras investigadoras que estudió la participación política femenina en el continente americano 
${ }^{12}$ Elsa M. CHANEY, 1992, p. 32.

${ }^{13}$ M. Eugenia DI DOMÉNICO, 1973, p.67.

${ }^{14}$ Carmen PUELMA, 1972, p. 40-1. fue Elsa M. Chaney, quien señala que la maternidad es una de las características asociadas a lo femenino que ha cruzado las posibilidades y el actuar de las mujeres en distintos ámbitos, lo que ha llevado a construir una imagen en que el único papel completamente aceptado para ellas es el de madres: "Cualquiera que fuera su posición social, el principal valor que se atribuía a la mujer era el de procrear hijos", ${ }^{12}$ el que se vincula, a su vez, con las limitaciones que han enfrentado para acceder a otros roles y con la generación de una autopercepción en que la maternidad ha cobrado centralidad. Por otro lado, considera que las ocasiones en que las mujeres han participado de manera activa en sus sociedades han sido cuando los espacios en que habitan y se desarrollan pasan por momentos de crisis, para luego retirarse del ámbito público, tesis que podría aplicarse a las actuaciones de las mujeres de derecha, como lo manifiesta la periodista chilena y candidata a diputada en 1973, Silvia Pinto, al explicar sus motivaciones.

De pronto, bruscamente, la mujer despertó y se lanzó a la pelea. Se dio cuenta que la política invadió su mundo y decidió luchar, olvidándose un poco de que era mujer, madre o esposa y volcándose por entero en la lucha política...

... Se han dividido familias completas por una ideología, lo que antes no sucedía en Chile. Cada uno dentro de una misma familia podía tener una ideología, pero principalmente por sobre todo, eran familias, amigos y seres humanos. El odio que se introdujo en el país ha sido lo que decidió a las mujeres, las violentó y las obligó a participar directamente en el terreno político. ${ }^{13}$

La situación que se vivía en cada país es significada por las mujeres de derecha como el justificativo para su inserción en la arena pública y en la política militante, es el momento, no ellas lo que las impulsa, situándose en un espacio que va en sus retóricas más allá de sus intereses, gustos y deseos personales, es algo que no se busca, sino que les tocó vivir y asumir, aún cuando algunas de ellas estaban en la política desde antes. Como señala en Chile Carmen Saenz, presidenta de las mujeres del Partido Nacional en los años 70: "Mi fe en la mujer, sin distinción de partidos políticos o situación económica, está en su tremenda intuición. Las chilenas no estamos entrenadas políticamente, pero sí estamos preparadas espiritualmente para oponernos a todo lo que dañe a la familia". ${ }^{14}$

La estrecha relación entre los roles de género asignados a las mujeres, en tanto madres, esposas y dueñas de casa y la acción socio-política femenina, también ha sido uno de los ejes medulares de las reflexiones en torno a 
15 POWER, 2005.

la participación de las mujeres, pues la maternidad ha sido utilizada de manera constante como justificación para sus salidas al espacio público. En este ámbito, resulta interesante señalar que tanto en Brasil como en Chile las mujeres que se movilizaron en contra de los gobiernos de João Goulart y Salvador Allende situaron el eje prioritario de su accionar en su condición de madres y por tanto de defensoras de sus hijos y familias, ante la amenaza que para ellas representaban las ideas marxistas.

Según Margaret Power, los valores que son defendidos por las mujeres de derecha se remiten a la afirmación de su rol maternal y a la naturalización de un destino instalado en el cuidado de sus familias; la oposición a los intentos de secularización de las sociedades y por tanto la defensa de la religión; la afirmación de sus valores culturales e identitarios a través de las ideas expresadas por la derecha y la búsqueda de seguridad y protección en la tradición, pues: "Para muchas de ellas, la derecha, que pretende conservar la "tradición" les ofrece seguridad y protección en contra de lo que les amenaza". ${ }^{15}$ Por su parte, Janaina Martins Cordeiro señala que en el caso de las mujeres brasileras, una de las aspiraciones centrales era la defensa de sus familias a partir del modelo establecido por el patriarcado, es decir que lo se defendía era precisamente la familia patriarcal, dentro de un esquema en que admiraban y eran influenciadas por sus 'patriarcas', pero también en el que realizaron sus propias construcciones en torno a las identidades de género a través de la reafirmación de los valores e instituciones que les parecían más importantes, como son: la familia, la religión y la patria. ${ }^{16}$

En este marco, las mujeres de derecha apuntaron a un modelo femenino que se sustentaba en los valores tradicionales otorgados a las mujeres, construyendo un discurso que negaba que sus acciones fueran políticas, pues consideraban que lo que las motivaba era la maternidad y no las ideologías. Sin embargo, adherían a las ideas levantadas por un sector político determinado y actuaban en el espacio público en base a ellas, construyendo un discurso en que buscaban situarse más allá de lo políico, lo que a su vez les servía para justificar sus acciones y sus posturas. Según Michéle Matellart, se configuró una especie de corporativismo femenino, a través del cual las mujeres fueron definidas como un cuerpo único a partir de los atributos que se les atribuían como naturales. ${ }^{17}$

Por otro lado, la adhesión de las mujeres a los postulados de la derecha también se puede conectar con algunas características de su desarrollo en la sociedad, pues hacia las décadas de 1960 y 1970 todavía era bajo el número de mujeres que trabajaban de manera asalariada 
18 POWER, 1997, p. 254.

\begin{abstract}
19 "La derecha tenía una habilidad especial para formular programas que respondieran a las necesidades de la mujer en el frente doméstico y en el frente público: les ofrecía soluciones concretas y al mismo tiempo rechazaba el argumento de que la mujer vivía oprimida". POWER, 2008, p.71.
\end{abstract}

fuera del hogar, encontrándose muchas veces alejadas de los debates políticos, lo que se unía a la centralidad que tenía dentro de los discursos y acciones de la izquierda el llegar y generar adhesión entre los trabajadores, los que por lo general eran hombres. ${ }^{18}$ En este sentido las mujeres eran un sujeto secundario dentro de las acciones de la izquierda, lo que no había sucedido con la derecha que, a partir de la conformación de instituciones de caridad y ayuda a los desvalidos, había generado contactos con las mujeres populares de larga data. ${ }^{19}$ Otro aspecto relevante para el caso de Brasil y Chile es la estrecha relación que había generado la iglesia católica con algunos sectores femeninos, lo que tuvo una fuerte expresión en las movilizaciones encabezadas por las brasileras.

En Chile se manifestó de manera clara durante el gobierno de Salvador Allende la necesidad de llegar a las mujeres, los planes de formar un Ministerio de la Familia iban en esa dirección, además de una serie de iniciativas que se desarrollaron a través de la Secretaria de la Mujer, situación que se entrelazaba con la importancia de asegurar resultados electorales contundentes que afianzaran y mostrarán el respaldo a la Unidad Popular. Muchas de estas medidas buscaron instar y facilitar su incorporación en el proceso revolucionario, pero desde una mirada que tendía a ubicarlas como complemento, como la otra mitad de lo masculino, como se expresaba en las palabras que siguen de Salvador Allende:

Está la realidad emancipadora asentada en los países que han derrotado el capitalismo, han construido o construyen el socialismo; por lo tanto, es la mujer un factor fundamental, esencial, en esta lucha combatiente de la pareja humana.

Nadie puede imaginarse una revolución emancipadora, constructora de una nueva sociedad, sin la presencia activa y combatiente de la mujer, amiga, hermana y compañera; de la mujer presente en todos los niveles del trabajo y la cultura.

De la mujer asumiendo la responsabilidad, por su capacidad de la mujer junto al hombre, sin desigualdades, y en función de una gran tarea común; de la mujer entregando a la revolución su ternura y su firmeza, que nace con un contenido más profundo porque es la madre la que siente más de cerca el dolor que emana del hambre de su hijo y del sufrimiento de los suyos por la injusticia de un régimen marcado todavía por la explotación imperialista. ${ }^{20}$

Por su parte Julieta Kirkwood también se ha referido a las formas de hacer política de las mujeres en Chile y América Latina, haciendo un análisis crítico de las formas 
${ }^{21}$ Julieta KIRKWOOD, 2010, p.35.

${ }^{22}$ Citado por MARTINS CORDEIRO, 2008, p.46 en que las izquierdas han relegado a un lugar secundario las problemáticas que las afectan, lo que junto con la construcción de una subjetividad tradicional en que la femineidad se ancla en la aceptación pasiva y sumisa del rol reproductor, la centralidad exagerada de lo afectivo, la extensión de lo doméstico en el ámbito laboral y profesional y la identificación a través del servicio a otros, considera que no resulta extraño que las mujeres hayan tenido una menor capacidad para participar "... en la definición de metas y objetivos sociales, políticos y económicos, salvo que sean planteadas como la defensa de su función natural". ${ }^{21}$

En este marco, las mujeres que participaron en las movilizaciones que incidieron en la desestabilización de los gobiernos de Goulart y Allende encontraron en las ideas sustentadas por la derecha una vinculación con sus propias creencias y posturas sobre cómo debían regirse ambos países, las hicieron suyas y las emplearon como un impulso para llegar a otras mujeres y a otros sectores sociales que manifestaban preocupaciones similares a las suyas. Su actuar no respondió sólo a la influencia de sus familias, de sectores políticos o de los medios de comunicación, sino que se relacionó de manera estrecha con el lugar que consideraban debían ocupar las mujeres en la sociedad y con la defensa de los valores y las instituciones que consideraban fundamentales.

\section{Las organizaciones de mujeres y las Marchas de la Familia, con Dios y por la Libertad: Brasil}

A inicios de la década del 60 , en el marco de la renuncia de Quadros y de la asunción de Goulart, surgieron en Brasil entidades civiles femeninas que se presentaban públicamente como asociaciones de madres, esposas y dueñas de casa, ${ }^{22}$ que tenían por objetivo alertar a la opinión pública de la presión que consideraban estaban viviendo las familias brasileras por causa del comunismo, además de apelar a la defensa de los hijos y de propagar la noción de que el marxismo buscaba separar a los niños de sus padres y madres. Junto con esto, levantaron como principios centrales de su accionar la construcción de un país cristiano y democrático, pues para ellas cualquier cercanía con el marxismo y el socialismo implicaba una amenaza para la democracia.

La primera organización que se creó fue la Unión Cívica Femenina (UCF) de São Paulo, en febrero de 1962; ese mismo año se fundó la Campaña de la Mujer Democrática (CAMDE). Un par de años después, en 1964, surgió la Liga de la Mujer Democrática de Belo Horizonte, la 
${ }^{23}$ IPES era un centro de estudios vinculado a la oposición a João Goulart, en donde confluían altos personeros de las elites brasileras.

${ }^{24}$ Citado por MARTINS CORDEIRO, 2008, p. 45.
Cruzada Democrática Femenina de Recife y la Acción Democrática Femenina Gaúcha, que se fundó en Porto Alegre bajo la orientación de la UCF.

La Campaña de la Mujer Democrática, CAMDE, se originó un año después de la renuncia de Jânio Quadros, constituyéndose a partir de un grupo de mujeres que frecuentaban la parroquia Nuestra Señora de la Paz en Ipanema (Río de Janeiro), luego de una reunión que hizo una de ellas en su casa, Amélia Molina Bastos, a la que asistieron algunas familias vinculadas a la iglesia, y dos altos dirigentes de IPES (Instituto de Investigaciones y Estudios Sociales). ${ }^{23}$ Según los relatos recogidos por Janaina Martins Cordeiro, estas mujeres tomaron conciencia, a partir de las palabras de algunos de los invitados, de que el país se encontraba amenazado, ante lo cual se reunieron 30 de ellas para elaborar y entregar al diario $\mathrm{O}$ Globo un manifiesto denominado Protesta Femenina. Luego de eso, en julio de 1962, hicieron el lanzamiento oficial de la organización en las dependencias del mismo diario, donde contaron con una cobertura importante a sus acciones. En sus convocatorias expresaban sus motivaciones centrales de la siguiente manera:

Convidamos às mulheres cariocas para uma manifestação cívica de fidelidade às liberdades democráticas que o comunismo tenta destruir em nosso país (...) A hora da reação é nossa, pois temos ainda, graças à democracia, o direito de falar e o respeito dos homens (...) Defendamos nossos lares, defendamos nossa Pátria. Já começamos a luta. Vamos lutar por um saneamento no Brasil, por uma vigilância cívica, pois a nós é dada a grande responsabilidade de povoar com bons brasileiros a nossa querida Pátria. Que cada Mulher seja um baluarte da Democracia, uma defensora da liberdade e uma agente de Deus. ${ }^{24}$

Dos fueron las líneas principales de acción de CAMDE, una de ellas se propuso la formación de las mujeres a través de la organización de cursos y conferencias, además de la constitución de un movimiento de opinión pública. La otra fue la presión constante hacia el gobierno a través de la realización de protestas y marchas, y del envío de cartas y telegramas al congreso. Eran mujeres de recursos que podían sostener un trabajo voluntario que durante algunos períodos fue bastante intenso; también se ha señalado que recibían recursos de otros lados, lo que es factible dada la cercanía que tuvieron estas agrupaciones con otras entidades como IPES.

Si bien las líderes de estos grupos femeninos pueden ubicarse como mujeres de sectores altos, es importante 
25 La tesis de Janaina Martins Cordeiro, releva el hecho de que la deslegitimación con que terminó la dictadura brasilera y la necesidad de generar consensos políticos que facilitaran el retorno a la democracia llevó a que se constituyera una memoria social que resalta las acciones de resistencia a la dictadura, estableciendo la idea de fue una postura generalizada la oposición civil, sin embargo esto ha impedido profundizar en torno al análisis de apoyo que hicieron civiles al régimen militar, atravesando también la propia memoria de las actoras que vivieron este período, pues en la actualidad no es correcto haber estado a favor de la intervención militar, lo que ha dificultado el estudio de experiencias como CAMDE. MARTINS CORDEIRO, 2008.

${ }^{26}$ Citado por MARTINS CORDEIRO, 2008, p.46. considerar que el discurso que desarrollaron en tanto madres en defensa de las familias tuvo el poder de apelar a sectores más amplios de la sociedad brasilera. El miedo a que el comunismo destruyera a la familia, la iglesia y la patria alcanzaba a más sectores de la sociedad brasilera, lo que permitió que CAMDE se extendiera a otras ciudades. El contacto que establecieron con otros sectores también fue intencionado por la agrupación, a través de la realización de cursos que destinaban a los sectores populares (concentrándose en algunas favelas), en los que enseñaban algunas herramientas prácticas, pero que también eran aprovechados para difundir sus ideas.

Durante los 12 años que funcionó CAMDE, la organización fue parte activa de tres coyunturas importantes. Por un lado, de la oposición al gobierno de João Goulart; por otro, de la demanda y legitimación de la intervención militar de 1964 y finalmente del apoyo y colaboración con el gobierno militar, donde se alinearon con el general Castello Branco, a quien entregaron su respaldo público. CAMDE dejó de funcionar en 1974, lo que parece vincularse con un alejamiento por parte de la organización del gobierno, lo que se puede relacionar con que no estuvieron de acuerdo con el curso que siguió la dictadura, aunque apoyaron y demandaron la implementación de medidas bastante duras. ${ }^{25}$

En cuanto a las marchas, la primera de ellas fue convocada en marzo de 1964, en respuesta a un discurso realizado por João Goulart el día 13 de ese mismo mes y año, en el que defendió las reformas que quería implantar su gobierno, ante un incidente ocurrido en un acto en que había participado su cuñado Leonel Brizola, donde un grupo de mujeres agitaron sus rosarios y se pusieron a rezar para evitar que Brizola hablara. Fue evidente que el discurso de Goulart apelaba a ese hecho, pues se refirió de manera directa al uso de los rosarios: "O cristianismo nunca foi o escudo para privilégios condenados para o Santo Padre, nem também, brasileiros, os rosários podem ser levantados contra a vontade do povo, que tem fé numa justiça social mais humana e na dignidade das suas esperanças". ${ }^{26}$ Discurso que fue considerado por sus opositores como una afrenta a la iglesia católica, ante lo cual se planteó la realización de una marcha en defensa del rosario, la que finalmente se convirtió en la Marcha por la Familia, con Dios y por la Libertad, pues usando este eslogan era posible llamar la atención de personas que no fueran católicas.

La primera marcha se efectuó en São Paulo el 19 de marzo, lo que pone de manifiesto la rapidez y efectividad con que se organizaron las mujeres, fue convocada por la UCF y contó con la participación de entre unas 500.000 a 
${ }^{27}$ MARTINS CORDEIRO, 2008, p.50.
${ }^{28}$ Sobre este punto, Margaret Power señala que: "La Campaña del Terror plantea dos aspectos importantes de las relaciones entre Estados Unidos y América Latina, a los que hasta ahora no se ha prestado mucha atención. Uno es que ya a comienzos de la década de 1960, y tal vez antes el gobierno de Estados Unidos aprovechó las ideas sobre género para fomentar el anticomunismo entre las mujeres latinoamericanas. El otro es que el gobierno de Estados Unidos y las fuerzas conservadoras de América Latina aprendieron con la experiencia mutua de movilizar a las mujeres contra gobiernos izquierdistas o progresistas, y aplicaron lo aprendido a sus propias situaciones". POWER, 2008, p.111.

${ }^{29}$ Silvia PINTO, 1972, p.14.
800.000 personas, lo que fue considerado como un éxito, porque demostraba la masividad de las demandas que estaban impulsando estas mujeres y la adhesión a ellas de otros sectores sociales. Al poco tiempo se organizaron otras marchas en otros puntos del país. CAMDE había convocado a una marcha en Río para el 2 de abril, pero el golpe se les adelantó, por lo que la marcha se transformó en una manifestación para celebrar la victoria militar y el derrocamiento de João Goulart. Según Janaina Martins Cordeiro, a esta manifestación asistieron alrededor de 1.000 .0000 de personas que conmemoraron la victoria de la cruz y el rosario por sobre la hoz y el martillo. ${ }^{27}$

\section{Las organizaciones de mujeres y las Marchas de las Cacerolas Vacía: Chile}

En 1963 se formó una organización compuesta por mujeres conservadoras de las elites, quienes, bajo el nombre de Acción Mujeres de Chile, se agruparon con un claro discurso anticomunista y en pos de evitar un posible triunfo de Salvador Allende. Dichas elecciones estuvieron marcadas por la realización de fuertes campañas en contra de Allende, las que en gran medida estuvieron dirigidas a las mujeres, a través de la construcción de discursos e imágenes que señalaban que las familias y por tanto las mujeres serían destruidas si ganaba el candidato socialista, empleando argumentos similares a los utilizados en Brasil en torno a que los niños serían alejados de sus padres. ${ }^{28}$

El triunfo de Salvador Allende en las elecciones de 1970 puso en alerta a las mujeres de derecha, en particular a las que estaban aglutinadas alrededor del Partido Nacional, quienes se movilizaron desde el momento mismo de la elección para evitar que asumiera la presidencia, para lo cual desfilaban en torno a La Moneda vestidas de luto, como una forma de demostrar la muerte de la democracia. Sin embargo, la elección fue finalmente ratificada por el Congreso. La periodista opositora, Silvia Pinto, relata de la siguiente manera los días posteriores a la elección de 1970.

Llegué a la conferencia de prensa. Phillips con Monjitas frente al departamento de Jorge Alessandri. En la calle un tumulto. Mujeres que habían ido a manifestar su adhesión al candidato derrotado. Él no se asomaría al balcón. Esta vez no en una actitud estudiada, sino porque no tenía que decirles a estas mujeres que se apiñaban frente a su domicilio. ¿A esperar qué?

- Sálvenos, por favor. ¿Qué va a pasar? ¿Vamos a tener de Presidente a ese hombre?...29 
Durante el primer año de gobierno no se realizaron manifestaciones mayores, pero el 1 de diciembre de 1971, se efectuó la primera Marcha de las Cacerolas Vacías, la que fue motivada por la oposición a algunas de las medidas tomadas por el gobierno y a la presencia de Fidel Castro en el país. Hasta ese momento la oposición había estado aletargada, pero la masividad de marcha logró sacudirlos y posicionar a las mujeres como un actor relevante. No está claro dónde, ni cómo, se originó la marcha, algunas hablan de que fue un acto más bien espontáneo, otras otorgan mayor relevancia a instancias partidarias de la derecha, pero lo que sí es evidente es que la marcha fue apoyada por los partidos políticos de oposición, lo que se expresó en la presencia de brigadas juveniles, compuestas por hombres del Partido Nacional, la Democracia Cristiana y del movimiento paramilitar, Patria y Libertad, que 'protegieron' el recorrido de las mujeres. Por su parte, el permiso para la realización de la marcha fue solicitado por un grupo de mujeres encabezado por la diputada del PN, Sylvia Alessandri.

Otro dato interesante es que hacia 1971 el desabastecimiento no había alcanzado las magnitudes que tuvo en años posteriores por lo que vincular la movilización a la escasez no tiene asidero, aunque los precios de los alimentos habían subido y algunos productos comenzaban a faltar. Después, efectivamente las cacerolas que golpeaban las mujeres en sus manifestaciones y en sus hogares se volvieron un símbolo de las dificultades que se enfrentaban en el país para acceder a bienes básicos de consumo. Sin embargo, el llamado a la marcha invocó a las dificultades que enfrentarían las mujeres para abastecerse y alimentar a sus hijos. La asistencia a la manifestación fue masiva y contó con una basta cobertura en los medios de prensa donde se hizo hincapié en los incidentes que hubo en torno a ella, acusando al gobierno de la UP de agredir a las mujeres que habían salido a marchar, las que eran identificadas como amas de casa que debían ser protegidas.

El éxito de esta primera marcha influyó de manera rápida en la conformación de las mujeres antiallendistas como un sector importante de la oposición, lo que se vinculaba, también, con la capacidad que podían desarrollar para conectarse con otros sectores de la sociedad y en particular con mujeres de otros segmentos sociales, pues se insistía, de manera similar a las experiencias desarrolladas en Brasil, en la apoliticidad de las acciones efectuadas por las mujeres, y en la configuración de un movimiento que apelaba a las mujeres en tanto madres, esposas y dueñas de casa. En este contexto, a comienzos de 1972 se formó Poder Femenino (PF), que era una instancia

832 Estudos Feministas, Florianópolis, 23(3): 817-837, setembro-dezembro/2015 
${ }^{30}$ Patricia GUZMÁN, 1972, p. 401 . compuesta por las mujeres de los partidos de oposición, las gremialistas y las independientes que se articularon para establecer un comité coordinador para la planificación de las actividades en contra del gobierno. Está organización funcionó hasta el golpe de Estado de septiembre de 1973.

Otra de las líneas de acción que tuvo PF fue la vinculación con mujeres de otros sectores sociales, lo que se logró en gran medida a través del apoyo que efectuaron a las esposas y familiares de los trabajadores que protagonizaron huelgas en contra del gobierno. Por otra parte, buscaron tender puentes para lograr la unidad de la oposición, lo que se relaciona con las concepciones que desarrollaron en torno a su neutralidad y apoliticismo, lo que las llevaba a considerarse como un espacio privilegiado para estimular el diálogo entre las mujeres de los distintos partidos de la oposición, como se señala en un reportaje de 1972 en la revista femenina EVA, donde se celebra la conformación de PF.

Para evitar cualquier malentendido, conviene insistir que, como en este movimiento hay nacionales, democratacristianas, radicales y padenistas, en ningún caso existe el ánimo de ir en contra de los partidos políticos o debilitar sus fuerzas. No se trata de formar un 'partido de mujeres'. Muy por el contrario. Lo que se pretende $-\mathrm{y}$ en eso son intransigentes - es que las directivas de sus colectividades imiten este ejemplo de unidad. Y sólo en la medida en que dejen sus diferencias a un lado serán respaldadas por este enorme poder que lo único que mira es el bien del país. ${ }^{30}$

Hacia 1973 los problemas políticos, sociales y económicos por los que pasaba Chile se habían agudizado, situación que no era ajena para las mujeres de Poder Femenino, quienes consideraban que los políticos y la oposición no estaban haciendo lo que debían, constituyéndose en la cara visible de los sectores que comenzaron a emplazar de manera pública la intervención de los militares, para lo cual se propusieron demandar la destitución de Allende, sacar al general Prats de la comandancia del ejército, crear un ambiente propicio para la intervención militar, animar a las fuerzas armadas para intervenir y movilizar a las mujeres para demostrar que una medida de este tipo tendría legitimidad. En agosto de ese mismo año se movilizaron por primera vez las esposas de los oficiales, las que se reunieron fuera del Ministerio de Defensa para protestar en contra del general Prats. La interpelación a los militares se realizaba por medio de la utilización de dos objetos simbólicos que les arrojaban: uno era el maíz y el otro eran plumas de aves, con lo que buscaban decirles que no fueran cobardes (gallinas). 
El 5 de septiembre convocaron a una nueva manifestación pública para exigir que Allende renunciara. Miles de mujeres participaron en la marcha en Santiago. Las movilizaciones, también, se replicaron en las provincias. Finalmente el 10 de septiembre, un día antes del golpe militar, las mujeres de PF, en conjunto con las esposas de los oficiales se reunieron fuera del Ministerio de Defensa, para pedir, una vez más, a las Fuerzas Armadas que intervinieran. Poco tiempo después del golpe, PF dejó de existir; el objetivo para el que se había conformado ya se había logrado y las características propias del golpe tampoco posibilitaban la acción de las organizaciones civiles, lo que se sumaba al discurso esgrimido por ellas mismas de que habían salido a la calle porque no habían tenido otra alternativa, pero que en el fondo esperaban volver a sus hogares o seguir en lo público, pero ahora ayudando a los desvalidos.

\section{Conclusiones}

Consideramos que organizaciones como CAMDE y PF sí tenían un componente político, el cual era negado por ellas mismas, pero es indudable que mantenían un contacto constante con dirigentes de partidos políticos, tenían acceso a información y recursos y establecían alianzas políticas y estratégicas. Además, contaron con la adhesión de sectores importantes de la ciudadanía, conformándose en un referente de las preocupaciones que afectaban a la población. Junto con esto, su accionar era planificado y buscaba influir en los espacios de poder. Sin embargo, ninguna de las dos organizaciones logró proyectarse mucho más allá del contexto en que fueron creadas, a pesar de que CAMDE siguió actuando después del golpe en Brasil.

Tanto en Brasil como en Chile, la incidencia que tuvieron las organizaciones de las mujeres de derecha fue de gran importancia para la legitimación de los golpes de Estado, lo que nos lleva en todo momento a pensar cuánto hubo de manipulación desde otros sectores y cuánto hubo de motivación propia, preguntas que todavía resultan difíciles de contestar de manera tajante, pues son planos que interactúan y se mezclan. Sin embargo, nos parece que su adhesión a las ideas de las derechas respondió a sus propios deseos y motivaciones; esto les permitió construir sus propios planos de acción, en los que también influyeron otros actores, pero sin desestimar que lo que estaban defendiendo era el modo de vida que creían correcto para ellas y para el conjunto de la sociedad.

Sobre el tipo de mujeres que compusieron estas organizaciones, cabe señalar que muchas de ellas, en especial las líderes, estaban vinculadas con las elites de la

834 Estudos Feministas, Florianópolis, 23(3): 817-837, setembro-dezembro/2015 
derecha tradicional, pero también lograron relacionarse y expresar demandas de las mujeres de los sectores medios y populares, pues apelaron a varios elementos que eran transversales a las mujeres, como es la defensa de la familia, la alimentación en el caso de Chile y el reforzamiento de los roles de género. Otros aspectos aglutinadores fueron el discurso anticomunista, el miedo a lo que significaba contar con gobiernos de estas características y el llamado a las mujeres a defender la patria y la religión. Este último aspecto fue particularmente importante en Brasil.

Nos resulta importante insistir en la relevancia de seguir investigando sobre los procesos políticos en que se han involucrado las mujeres, ya sea desde el sistema político formal o desde la conformación de organizaciones civiles que han apuntado a objetivos que pueden ser entendidos como políticos, pues es importante conocer cuáles son los objetivos, concepciones y estrategias que han desarrollado, las que, como hemos visto en algunos casos, en vez de aspirar a la emancipación por medio de la trasgresión de los horizontes otorgados a lo femenino, se han dirigido, más bien, a la reafirmación de los roles tradicionales que se han asignado a las mujeres y a la defensa, incluso por medio de la sedición y de la actuación en el espacio público, de las ideas tradicionales de los sectores conservadores.

¿Cómo han hecho política las mujeres? ¿Han hecho política de una manera distinta? Son preguntas que siguen cobrando actualidad, pues a la luz de distintas experiencias protagonizadas por mujeres durante el siglo XX se puede señalar que hay un tránsito permanente entre los deseos de cambio y la mantención de las nociones establecidas para lo femenino, para lo que se vuelve interesante problematizar las formas en que se han desarrollado los actuares políticos femeninos, pues ya sean estos inspirados por ideologías de derecha o de izquierda han tendido en ambos casos a concebir a las mujeres centralmente como madres, situación que nos lleva a preguntarnos sobre cómo o en qué aspectos se mantienen hasta hoy estas nociones e influyen en la mantención de las normas tradicionales de género y en la aún baja representación femenina en instancias de toma de decisión.

¿Qué resultados han tenido los usos políticos estratégicos que se han otorgado a la maternidad? es una pregunta que queda abierta, así como cuáles son las maneras más adecuadas para desarticular los dispositivos culturales que siguen manteniendo a las mujeres en una posición secundaria en la vida cotidiana y en el ejercicio de la política. ¿Estos pueden ser desactivados si se sigue relevando la imagen de mujer-madre? Son preguntas que pueden indicar que es momento de problematizar los 
espacios seguros en que lo femenino se ha insertado en la política, a partir de la todavía estrecha asociación de lo femenino con lo doméstico y lo maternal, negando en ocasiones sus propios intereses, ideologías y aspiraciones, negando en definitiva el carácter político de los actuares públicos femeninos.

\section{Referencias}

BERLINER, Ivonne. Chilenas de sectores medios con valores conservadores como sujetos políticos: 1964 - 1989. 2005. Tesis (Doctorado en Historia, mención Historia de Chile) Departamento de Historia, Facultad de Filosofía y Humanidades, Universidad de Chile. Santiago.

CHANEY, Elsa M. Supermadre. La mujer dentro de la política en América Latina. México D. F: Fondo de Cultura Económica, 1992.

DEL POZO, José. Historia de América Latina y del Caribe. 1825 - 2001. Santiago: LOM Ediciones, 2002.

GARCÉS, Joan. Soberanos e intervenidos. Chile, la Guerra Fría y después. Santiago: Ediciones BAT, 1995.

HALPERIN DONGI, Tulio. Historia Contemporánea de América Latina. 6a Edición. Buenos Aires: Alianza, 1999.

KIRKWOOD, Julieta. Ser política en Chile. Las feministas y los partidos. 3a Edición. Santiago: LOM Ediciones/FACSO, 2010.

MATELLART, Michèle. La cultura de la opresión femenina. México: Serie popular ERA, 1977.

MARTINS CORDEIRO, Janaina. 'A Nação que se salvou a si mesma'. Entre memória e história, a Campanha da Mulher pela Democracia (1962 - 1974). 2008. Tesis (Magíster en Historia) - Departamento de Historia, Universidad Federal Fluminense. Publicación electrónica, ver: http://www.histo ria.uff.br/stricto/teses/Dissert-2008_CORDEIRO_Janaina_ Martins-S.pdf.

MARTINS CORDEIRO, Janaina. "O 'risco da incompreensão': Memória e identidade na autobiografia de uma exdiretora da Campanha da Mulher pela Democracia (CAMDE)". 2008. Publicación electrónica, ver: http://www. historia.uff.br/nec/sites/default/files/O_risco_da_incompre ensao_0.pdf.

PINTO, Silvia. Los días del arco iris. Santiago: Editorial del Pacífico, 1972.

POWER, Margaret. "La Unidad Popular y la masculinidad". En La Ventana $n^{\circ}$ 6, 1997. Publicación electrónica, ver: http://148.202.18.157/sitios/publicacionesite/pperiod/ laventan/Ventana7/ventana7-7.pdf.

POWER, Margaret. "La mujer de la derecha en América Latina y en el mundo: Una perspectiva comparativa". Revista de

836 Estudos Feministas, Florianópolis, 23(3): 817-837, setembro-dezembro/2015 
Estudios Históricos, Universidad de Chile: Facultad de Filosofía y Humanidades. Departamento de Ciencias Históricas, vol. 2, n० 1, agosto 2005. Publicación electrónica, ver: http://www.estudioshistoricos.uchile.cl/CDA/ est_hist_impresion/0,1476,SCID\%253D15006\%252 6ISID\% 253 D540,00.html.

POWER, Margaret. La mujer de derecha. El poder femenino y la lucha contra Salvador Allende, 1964 - 1973. Santiago: DIBAM - Centro de Investigaciones Barros Arana, 2008.

SKIDMORE, Thomas E. y SMITH, Peter H. Historia contemporánea de América Latina. América Latina en el siglo XX. Barcelona: Crítica - Grijalbo Mondadori S. A., 1996.

Revista EVA - Chile (1970-1973)

PUELMA, Carmen. "Carmen Saenz: hija de la libertad de pensamiento". Revista EVA, marzo 1972, p. 40-1.

GUZMÁN, Patricia. "Poder Femenino iiAl ataque!!". Revista Eva, septiembre 1972, p.40-1.

DI DOMÉNICO, M. Eugenia. "La mujer en la política. El odio impulsó a las chilenas" (entrevista a Silvia Pinto). Revista Eva, febrero 1973, p.67.

\title{
Discursos Salvador Allende (Chile)
}

Salvador Allende. Palabras del Presidente de la República, compañero Salvador Allende Gossens, en el Seminario "La mujer de hoy en América Latina" efectuado en el edificio Gabriela Mistral, Santiago, 27 de octubre de 1972. Publicación electrónica, ver: http://www.salvador-allende.cl/ Discursos/1972/27_octubre_1972.pdf.

[Recebido em 4 de junho de 2014 , e aceito para publicação em 7 de maio de 2015]

\begin{abstract}
Right wing women and the mobilizations against the governments of Brazil and Chile (1960 and 1970)

Abstract: 40 years after the Chilean military coup d'état in Chile (1973) and 50 years after the coup in Brazil (1964), it is interesting to analyze and compare the demonstrations and protest actions that right-wing women (middle class and bourgeois women) led in order to destabilize the governments of Goulart and Allende. In both countries these women led successful campaigns against the constitutionally elected governments. For this objective, they gathered together, established coalitions with other sectors, received increased support, went out to the public space, demanded the resignation of the president and called for other women to speak out against the Marxism and the defense of the homeland, the order and the family. These women's actions and their effectiveness were deeply marked by the defense of the traditional gender roles and the conceptions of women's political participation which tended to deny the political nature of the women's performance.
\end{abstract}

Key Words: Gender; dictatorships; political participation. 